\section{Impact of Pharmacy Ambulatory Care Services in Managing Patients with Diabetes in an Indigent Population Clinic: A Case Review Study}

\author{
Justine M Latif, PharmD*
}

Ambulatory Care Pharmacist, Lloyd L. Gregory School of Pharmacy, Palm Beach Atlantic University, Florida, USA

\begin{abstract}
Purpose: The purpose of this study was to assess the benefit of pharmacist ambulatory care services in the management of patients with uncontrolled diabetes in an indigent population clinic.

Methods: Patients with uncontrolled diabetes were referred to the pharmacist diabetes clinic (PDC) for diabetes management. The pharmacist collected, recorded, and assessed baseline and follow-up subjective and objective information during each appointment. Patients included for data collection were those referred to the PDC with uncontrolled diabetes despite previous health care provider management. Patients were excluded if another specialist was required to intervene in the care of the patient's diabetes or if the patient did not follow-up at least once. The primary outcome was change in hemoglobin A1c (HgbA1c). The secondary outcomes were changes in fasting blood glucose (FBG), random blood glucose (RBG), number of patients experiencing hypoglycemic events, number of patients experiencing nocturia, the implementation of daily foot inspections, and medications prescribed prior to and after pharmacist intervention.
\end{abstract}

Results: A paired t-test was conducted for objective lab values to assess the statistical significance of change prior to and after pharmacist intervention. Patients' HgbA1c averaged $12.1 \%$ before and $9.8 \%$ after pharmacist intervention $(95 \% \mathrm{Cl}, 0.656$ to $3.884 ; \mathrm{p}=0.0112)$. FBG levels averaged $198 \mathrm{mg} / \mathrm{dL}$ before and $147 \mathrm{mg} / \mathrm{dL}$ after

*Corresponding author: Justine M Latif, PharmD, Ambulatory Care Pharmacist Lloyd L. Gregory School of Pharmacy, Palm Beach Atlantic University, Florida, USA, Email: JUSTINE_LATIF@pba.edu

Citation: Latif JM (2020) Impact of Pharmacy Ambulatory Care Services in Managing Patients with Diabetes in an Indigent Population Clinic: A Case Review Study. J Gastroenterol Hepatology Res 5: 029.

Received: June 14, 2020; Accepted: June 25, 2020; Published: June 30, 2020

Copyright: (c) 2020 Latif JM. This is an open-access article distributed under the terms of the Creative Commons Attribution License, which permits unrestricted use, distribution, and reproduction in any medium, provided the original author and source are credited. pharmacist intervention ( $95 \% \mathrm{Cl},-12.23$ to 168.23 ; $p=0.0841$ ). RBG levels averaged $234 \mathrm{mg} / \mathrm{dL}$ before and $199 \mathrm{mg} / \mathrm{dL}$ after pharmacist intervention $(95 \% \mathrm{Cl}, 2.58$ to $202.14 ; \mathrm{p}=0.0453)$. Four patients reported an average of 2 monthly hypoglycemic events before and 3 patients reported an average of 1 monthly hypoglycemic event after pharmacist intervention. Three patients before and 10 patients after pharmacist intervention checked their feet daily. Twelve patients before and 8 patients after pharmacist intervention experienced nocturia. Medication modifications decreased adverse events, intolerance, and hypoglycemia.

Conclusion: Clinical pharmacist diabetes management provided a decrease in $\mathrm{HgbA} 1 \mathrm{c}$ by $2.3 \%$, FBG by $51 \mathrm{mg} / \mathrm{dL}$, and RBG by $35 \mathrm{mg} /$ dL. Statistical significance was found with the change in $\mathrm{HgbA} 1 \mathrm{c}$ and RBG values. Number of patients experiencing hypoglycemia and nocturia decreased after pharmacist intervention while the number of patients who checked their feet daily increased after pharmacist intervention. Medication regimens decreased adverse events, intolerance, and hypoglycemic events.

\section{Introduction}

According to the Centers for Disease Control and Prevention's (CDC) National Diabetes Statistics Report of 2017, 30.4 million Americans (9.4\%) in 2015 had either type 1 or type 2 diabetes and 84.1 million Americans had prediabetes [1]. Approximately 25\% of the adults living with diabetes did not know they were diagnosed with the condition and only $12 \%$ of the adults with prediabetes knew they were at an increased risk of developing diabetes. Rowley et al conducted a study to project the prevalence of diabetes in the future and according to the Institute for Alternative Futures Diabetes 2030 Mod$\mathrm{el}$, there is projected to be a $54 \%$ increase in diabetes prevalence from 2015 to 2030 [2]. Another projection study was conducted by Boyle et al for the burden of diabetes in the US adult population in 2050. Their study projected an increase in diabetes cases from 8 cases per 1,000 from 2008 to about 15 cases per 1,000 in 2050; however, it was stated that this could be due to an increased population of overall high-risk minority groups [3].

As the prevalence of diabetes increases in America, it is anticipated that the economic cost associated with the condition will increase as well. The American Diabetes Association (ADA) conducted a cost-study analysis to assess the economic burden of diabetes in the United States which demonstrated that the cost of diagnosed diabetes continues to increase annually $[1,4]$. In 2017, it was estimated that the overall cost associated with patients diagnosed with diabetes was $\$ 327$ billion, $\$ 237$ billion of which was related to direct medical costs and $\$ 90$ billion to reduced productivity [4]. In patients diagnosed with diabetes, not only does the direct cost of diabetes management become a concern, but also the secondary effects that result from the condition being uncontrolled [5-7]. There are increased risks for developing secondary conditions and complications in patients with diabetes, with the most life-threatening being macrovascular complications, particularly cardiovascular events as a result of decreased 
renal function [5-7]. Microvascular complications such as neuropathy, retinopathy, and nephropathy are also very common complications in patients with uncontrolled diabetes and can lead to chronic neuropathic pain, blindness, kidney disease, and increased medical costs [7-11].

Aside from macro-and microvascular complications, multiple studies have shown that diabetes also has a direct correlation in the development of psychiatric conditions, such as depression and Alzheimer's, particularly in low socio-economic societies [12-15]. One of the leading causes of uncontrolled diabetes in low socio-economic societies is associated with food insecurity, which is defined as an unreliable access to healthy, affordable food..$^{16} \mathrm{~A}$ study assessed the relationship between food insecurity, depression, and diabetes among low-income patients, showing that $47.4 \%$ of the patients with food insecurity were more likely to be depressed (40.7\% vs. $15.4 \%)$, have low medication adherence $(52.9 \%$ vs. $37.2 \%)$, and report diabetes distress $(55.2 \%$ vs. 33.8\%)[16].

With the increased number of patients with diabetes, it can be challenging for healthcare providers to provide diabetic patients with lifestyle, dietary, and medication counseling as well as frequent follow-up appointments. Fortunately, in some states, and even countries, pharmacists have established provider status or are able to work under a collaborative practice agreement with other healthcare providers in order to manage patients with chronic conditions, one of those being diabetes. A study was completed by Schultz etal. to assess the clinical outcomes of a pharmacist-managed diabetes clinic compared to primary care providers [17]. It was found that the change in patients' hemoglobin A1c (HgbA1c) in the pharmacist-managed clinic was $-1.63 \%$ versus $+1.53 \%$ in the primary care providers' patients [17]. Another study completed in Asia evaluated the clinical outcomes of diabetes care in a multidisciplinary collaborative care versus physician-centered care. At 6 months, patients' HgbAlc reduced from $8.6 \% \pm 1.5 \%$ at baseline to $8.1 \% \pm 1.3 \%$ in the intervention arm while the HgbAlc in the control arm remained unchanged at 6 months [18]

Delegating ongoing diabetes care to other qualified clinicians and healthcare providers can aid in the reduction of the negative economic impact associated with uncontrolled diabetes. Additionally, targeted and frequent patient counselling and education sessions can help improve patient accountability and self-efficacy in managing their condition (s). These studies indicate there is a potential service that pharmacists can provide in managing patients with chronic conditions to improve overall patient care. The purpose of this case review study is to assess the feasibility of pharmacist ambulatory care services in the management of patients' uncontrolled diabetes in an indigent population clinic.

\section{Methods}

This IRB-approved study was peer-reviewed and operated by an indigent clinic's staff which included a clinical pharmacist, an internal medicine practitioner, and a Chronic Disease Clinic Manager. Patients qualified to receive care at the indigent clinic with uncontrolled diabetes were referred by the Chronic Disease Clinic Manager to the clinical pharmacist's diabetes clinic (PDC) for diabetes management. The clinical pharmacist providing the services in the PDC provided residency-trained expertise in the management of the patients' diabetes. Under a collaborative practice agreement with the clinic, the pharmacist had the ability to start or stop any medication a patient was prescribed, modify the dose of a patient's medication (s) related to diabetes, prescribe medication (s) to be dispensed from the clinic's dispensary, and order blood work to be drawn for diabetes assessment. During each appointment, the patient received a one-on-one session with the clinical pharmacist in which a thorough, guideline-based analysis of the patient's diabetes was conducted. The pharmacist asked the patient questions that would aid in the indication of controlled or uncontrolled diabetes such as symptoms of hyperglycemia (i.e. polyuria, polyphagia, polydipsia, fatigue, etc.), hypoglycemic events, nocturia, symptoms of neuropathy (i.e. tingling in the fingers or toes, loss of sensation in extremities, paresthesia, etc.), and any abnormalities in the feet (i.e. ulcers, cuts that do not heal, unknown injuries, bruises, etc.). The pharmacist also assessed the patient's regular diet throughout the day. Counseling was provided regarding which foods tend to increase blood glucose levels and which foods do not. The pharmacist would identify foods in the patient's diet that could be the cause of uncontrolled blood glucose levels and would discuss ways to reduce, replace, or eliminate said foods with the patient.

After collecting the patient-reported information, the pharmacist assessed the patient's most recent objective information. This included an analysis of home blood glucose logs, clinic blood glucose readings, comprehensive metabolic panel (CMP), HgbAlc, lipid panel, microalbuminuria, thyroid-stimulating hormone (TSH), liver function tests (LFTs), and the patient's last retinal exam, if available. After assessing the patient's reported subjective and objective information, the pharmacist developed a specific plan for the patient, including lifestyle modifications, diet counseling, guideline-based medication modifications and counseling, and, if needed, order blood work to be done. Follow-up appointments were made in the future to assess the efficacy of the executed plan and the patient's condition. If needed, modifications to their plan were made at each follow-up appointment.

Patients included for data collection included were those referred to the PDC with diabetes (both type 1 and 2) who were previously managed by another health care provider (HCP) in the clinic and remained uncontrolled despite previous HCP care. Patients were excluded from the data analysis if they had a condition in which another specialist needed to intervene in the care of the patient's diabetes or if the patient did not follow-up with the PDC at least once.

Once a patient was referred to the PDC, the patient's baseline information that was present in the clinic's electronic medical record, Athena Health ${ }^{\circledR}$, was documented on a spreadsheet. Data collected for the study included the patient's age, gender, ethnicity, and the type of diabetes diagnosed. The patient-reported subjective information was collected and included the frequency of hypoglycemic events that occur monthly, presence of nocturia, whether or not the patient checks their feet daily, number of previous HCP visits, and the diabetes medication (s) the patient presented to the PDC with. The objective data collected included the patient's HgbA1c, fasting blood glucose readings (FBG), and random/post-prandial blood glucose readings (RBG). With each follow-up appointment, the progress of the patient's condition was documented on the spreadsheet for future data analysis.

The primary outcome of the study was to assess change in $\mathrm{Hg}$ bA1c after PDC management. The secondary outcomes of the study assessed changes in FBG levels, changes in RBG levels, number of patients experiencing hypoglycemic events monthly, changes in 
Citation: Latif JM (2020) Impact of Pharmacy Ambulatory Care Services in Managing Patients with Diabetes in an Indigent Population Clinic: A Case Review Study. J Gastroenterol Hepatology Res 5: 029.

nocturia presence, the implementation of the patient checking their feet daily for any abnormalities after pharmacist education, and the medications prescribed for diabetes management prior to and after pharmacist intervention.

\section{Results}

Patients who were referred to the PDC from November 2018 until June 2019 were included in this study's data collection. A total of 17 patients met the inclusion criteria and were included for data collection, with their demographic information listed in Table 1. A paired t-test was conducted for the primary and secondary objective values in order to assess statistical significance in the intervention. The patients seen by the PDC had a range of 2-28 previous HCP visits in the clinic with an average of 11 previous HCP visits per patient. Each patient had an average of 4 visits in the PDC with the clinical pharmacist in which their guideline-recommended subjective reports (i.e. number of hypoglycemic events, checking feet daily, nocturia presence, etc.), blood glucose levels, and blood work were assessed.

\begin{tabular}{|c|c|c|}
\hline \multicolumn{3}{|l|}{ Gender } \\
\hline & Male & 13 \\
\hline & Female & 4 \\
\hline \multicolumn{3}{|c|}{ Ethnicity } \\
\hline & Caucasian & 1 \\
\hline & Hispanic & 16 \\
\hline \multicolumn{3}{|l|}{ Age } \\
\hline & $20-40$ & 2 \\
\hline & $41-60$ & 11 \\
\hline & $61+$ & 4 \\
\hline \multicolumn{3}{|c|}{ Diagnosis } \\
\hline & Type 1 DM & 0 \\
\hline & Type 2 DM & 17 \\
\hline
\end{tabular}

Prior to pharmacy services, patients' HgbA1c averaged at $11.4 \%$ compared to $9.1 \%$ after pharmacy intervention $(95 \% \mathrm{CI}, 0.656$ to 3.884; $\mathrm{p}=0.0112$ ) (Table 2). FBG levels prior to pharmacy intervention averaged at $252 \mathrm{mg} / \mathrm{dL}$ compared to $174 \mathrm{mg} / \mathrm{dL}$ after pharmacy intervention ( $95 \% \mathrm{CI},-12.23$ to 168.23 ; $\mathrm{p}=0.0841)$ (Table 2). RBG levels averaged at $257 \mathrm{mg} / \mathrm{dL}$ prior to pharmacy intervention compared to $157 \mathrm{mg} / \mathrm{dL}$ after pharmacy intervention (95\% CI, 2.58 to 202.14; $\mathrm{p}=0.0453$ ). Prior to pharmacist intervention, four patients reported an average of 2 hypoglycemic events per month and only six patients checked their feet daily for injuries and/or abnormalities. After pharmacist intervention, three patients reported an average of 1 hypoglycemic event per month. Fourteen patients reported checking their feet daily for any injuries and/or abnormalities. Twelve patients prior to pharmacist intervention experienced nocturia at a range of $0-5$ times/night while 8 patients after pharmacist intervention experienced nocturia at a range of 0-4 times/night (Table 2).

Medication the patients were prescribed to take before and after the pharmacist intervention are listed in Table 3. There was a decrease in the patients prescribed insulin, metformin, a sodium-glucose co-transporter-2 inhibitor (SGLT-2i), and dipeptidyl peptidase-4 inhibitor (DPP-4i). The medications prescribed were either dispensed through the clinic's dispensary or were supplied through the medication's Patient Assistance Program (PAP) if the patient met the PAP's qualifications and was approved to receive the medication from the PAP. Careful monitoring of all medications was done during visits to ensure the safety of the patient's health.

\begin{tabular}{|c|c|c|c|}
\hline Results & $\begin{array}{c}\text { Average } \\
\text { Before }\end{array}$ & $\begin{array}{c}\text { Average } \\
\text { After }\end{array}$ & Difference \\
\hline Alc (average in \%) & 11.4 & 9.1 & -2.3 \\
\hline Fasting blood glucose (mg/dL) & 252 & 174 & -78 \\
\hline Random blood glucose (mg/dL) & 257 & 157 & -100 \\
\hline Hypoglycemic events (per month) & 2 & 1 & -1 \\
\hline Patients who check their feet daily (N=17) & 6 & 14 & +8 \\
\hline Patients experiencing nocturia (N=17) & 12 & 8 & -4 \\
\hline
\end{tabular}

Table 2: Primary and Secondary Outcome Results.

\begin{tabular}{|c|c|c|}
\hline Medication & Before & After \\
\hline Insulin* $^{*}$ & 7 & 6 \\
\hline TTD 0-10 units & 0 & 0 \\
\hline TTD 11-20 units & 3 & 2 \\
\hline TTD 21-30 units & 1 & 2 \\
\hline TTD 31+ units & 3 & 2 \\
\hline Metformin & 8 & 7 \\
\hline 500 mg PO BID & 1 & 0 \\
\hline 1000 mg PO BID & 7 & 7 \\
\hline SGLT-2 inhibitor & 2 & 1 \\
\hline DPP-4 inhibitor & 2 & 0 \\
\hline GLP-1 receptor agonist & 1 & 3 \\
\hline Sulfonylurea & 2 & 2 \\
\hline
\end{tabular}

Table 3: Prescribed Medication.

*TDD = total daily dose; includes all forms of insulin (i.e. basal, intermediate, bolus, etc.)

\section{Discussion}

The PDC provided many beneficial services during each patient interaction. The pharmacist was able to provide more frequent follow-up visits with the patient for a longer duration of quality time than the patient may have received with another HCP in the clinic. During each appointment with the clinical pharmacist, patients were encouraged to discuss obstacles or difficulties they frequently encountered that would prevent blood glucose control. A customized plan was developed by the pharmacist and patient to involve the patient in the management of their condition. In addition to lifestyle modifications, medications would also be modified during patient visits. With a clinical pharmacist providing the service, all medications taken by the patients were automatically reviewed for accurate indications to avoid any redundancies in medications and to ensure there were no drug-drug or drug-disease interactions. If a patient's diabetes regimen was to be modified, the patient would be given guideline-based options for alternative or additional medications to choose from with the benefits and possible side effects of each option, also allowing for patient involvement in controlling their condition. The medication would then be dispensed from the clinic's dispensary, free of charge to the patient, to ensure the patient received the medication(s). The patients were also given the option to apply to a PAP if offered by the 
manufacturer of their prescribed medication and if the patient met the manufacturer's application requirements. Once approved by the PAP, the approved medication would be delivered by the PAP to the clinic and the patient would be contacted to retrieve their medication from the clinic's dispensary.

The study's primary outcome was to assess change in the patients' HgbA1c prior to and after pharmacist intervention. This objective marker was designated to be the primary outcome as it provides an overall review of the patient's blood glucose values for the prior 3 months with minimal error. As mentioned in the study's methods, the patients were instructed to test their blood glucose levels at home at least twice daily, with one of those tests being a FBG value. Patients' home blood glucose logs were brought and assessed at every appointment. It should be noted, however, that there may have been a variability in compliance and frequency of home blood glucose monitoring or the patient may have altered the blood glucose values recorded in order to appear to have controlled values. Thus, the HgbA1c was chosen to be the primary outcome as this objective value provides a more accurate marker to assess change in control of the patients' diabetes.

All patients who presented to the PDC on insulin therapy were evaluated for the increased risk of hypoglycemia based off their weight, diet, lifestyle, past frequency of hypoglycemic events, and other medications prescribed. One patient's insulin was discontinued due to consistent hypoglycemic events despite modifications to diet and changing from a mixed basal/bolus insulin to just a basal insulin. The second patient was prescribed a DPP-4i along with the insulin and the DPP-4i was discontinued due to a history of frequent hypoglycemic events and hypoglycemia was not experienced afterwards. All patients with type 2 diabetes mellitus (T2DM) were prescribed the maximum tolerated dose of metformin. Despite guideline-based recommendations of metformin therapy, two patients with T2DM had intolerable adverse events (gastrointestinal upset unresolved with slow titration or food) and were discontinued from metformin therapy. One patient presented to the PDC on 500 milligrams (mg) of metformin to be taken twice daily and this patient's metformin was maximized to $1000 \mathrm{mg}$ to be taken twice daily. One patient who presented to the PDC with an SGLT-2i had an increased frequency in urination and, despite guideline recommendations and cardiovascular benefit of the SGLT-2i, the patient had to discontinue the agent due to their job and active lifestyle. These clinical interventions aided patients in the improvement of their lifestyle and in their diabetes control.

In addition to these medication therapy management services, the pharmacist was able to order and assess patients' objective lab values under the collaborative practice agreement in order to monitor the progress of the patients' diabetes as well as the safety of the medication(s) the patients were taking. A majority of the patients seen in the clinic were Spanish-speaking, and it was a great benefit that the pharmacist providing the clinical interventions was able to communicate with professional competency in Spanish. Through the results of this case review study, it is demonstrated that an improvement in $\mathrm{HgbA1c}$, blood glucose control, and overall well-being of the patient was noted with clinical pharmacist intervention.

Despite the benefits seen from the PDC, there were some limitations encountered during this study. This case review study was conducted with a limited number of patients and should be conducted at a larger scale in the future to assess the short-term and long-term clinical significance of clinical pharmacists managing patients with diabetes in an indigent clinic. As mentioned previously, services provided were completed in an indigent clinic. A common socioeconomic complication encountered was transportation. Some patients were unable to be present for frequent follow-up appointments due to the expenses of using public transportation or being dependent on a family member or friend for transportation and not having the flexibility to come to their follow-up appointments. The increased time between appointments could have led to unmotivated control of their condition or running out of medication and not being able to refill the medication until the next appointment. Despite this complication, patients were still encouraged to present to the clinic as a "walk-in", when possible, to be seen by the pharmacist. Patients who were unsure if they could attend the follow-up appointment or those with a history of not showing up for follow-up appointments were dispensed an extra month's supply of medication to ensure a sufficient supply of the medication until the next appointment. Additionally, in order to avoid missing appointments, patients were reminded of their follow-up appointment the day prior.

As previously mentioned, all the patients seen by the PDC spoke a language other than English. The pharmacist providing the clinical services was able to communicate with Spanish-speaking patients and interpreters were available in the clinic for Creole-speaking patients; however, some words and specific meanings could have still been lost in translation despite professional competency in a multilingual staff. A future study should be conducted to assess the external validity of this study and its extrapolation to the general population. This study should include a larger number of patients who receive the intervention with various demographic and socioeconomic backgrounds.

\section{Conclusion}

After clinical pharmacist management of patients diagnosed with diabetes in an indigent population clinic, an overall decrease in $\mathrm{Hg}$ bA1c by $2.3 \%$, FBG levels by $78 \mathrm{mg} / \mathrm{dL}$, and RBG levels by $100 \mathrm{mg} /$ $\mathrm{dL}$ was observed. Additionally, the number of patients with symptoms of uncontrolled diabetes, such as hypoglycemia and nocturia, was decreased and 14 of the 17 patients conducted daily foot inspections for any abnormalities after pharmacist counseling. Patients' medications were reviewed and modified based off of tolerability, frequency of adverse events, and lifestyle. Future studies should be conducted at a larger scale to assess short-term and long-term clinical effects on cardiovascular and mental health.

\section{References}

1. Centers for Disease Control and Prevention (2017) National Diabetes Statistics Report, 2017. Centers for Disease Control and Prevention, U.S. Dept of Health and Human Services, Atlanta, GA, USA.

2. American Diabetes Association (2018) Economic Costs of Diabetes in the U.S. in 2017. Diabetes Care 41: 917-928.

3. Rowley WR, Bezold C, Arikan Y, Byrne E, Krohe S (2017) Diabetes 2030: Insights from Yesterday, Today, and Future Trends. Popul Health Manag 20: 6-12.

4. Boyle JP, Thompson TJ, Gregg EW, Barker LE, Williamson DF (2010) Projection of the year 2050 burden of diabetes in the US adult population: Dynamic modeling of incidence, mortality, and prediabetes prevalence. Popul Health Metr 8: 29. 
5. Xu WL, Von strauss E, Qiu CX, Winblad B, Fratiglioni L (2009) Uncontrolled diabetes increases the risk of Alzheimer's disease: A population-based cohort study. Diabetologia 52: 1031-1039.

6. Nguyen AL, Green J, Enguidanos S (2015) The relationship between depressive symptoms, diabetes symptoms, and self-management among an urban, low-income Latino population. J Diabetes Complicat 29: 1003 1008 .

7. Cleal B, Panton UH, Willaing I, Holt RIG (2017) Diabetes and depression in Denmark 1996-2010: National data stratified by occupational status and annual income. Diabet Med 34: 108-114.

8. Nag S, Bilous R, Kelly W, Jones S, Roperet N, et al. (2007) All-cause and cardiovascular mortality in diabetic subjects increases significantly with reduced estimated glomerular filtration rate (eGFR): 10 years' data from the South Tees Diabetes Mortality study. Diabet Med 24: 10-17.

9. Cea Soriano L, Johansson S, Stefansson B, Rodríguez LAG (2015) Cardiovascular events and all-cause mortality in a cohort of 57,946 patients with type 2 diabetes: Associations with renal function and cardiovascular risk factors. Cardiovasc Diabetol 14: 38.

10. Navarro-pérez J, Orozco-beltran D, Gil-guillen V, Pallares V, Valls F, et al. (2018) Mortality and cardiovascular disease burden of uncontrolled diabetes in a registry-based cohort: the ESCARVAL-risk study. BMC Cardiovasc Disord 18: 180.

11. Van der meer V, Wielders HP, Grootendorst DC, de Kanter JS, Sijpkens YWJ, et al. (2010) Chronic kidney disease in patients with diabetes mellitus type 2 or hypertension in general practice. Br J Gen Pract 60: 884-890.
12. Afkarian M, Sachs MC, Kestenbaum B, Hirsch IB, Tuttle KR (2013) Kidney disease and increased mortality risk in type 2 diabetes. $\mathrm{J}$ Am Soc Nephrol 24: 302-308.

13. Stratton IM, Adler AI, Neil HA, Matthews DR, Manley SE, et al. (2000) Association of glycaemia with macrovascular and microvascular complications of type 2 diabetes (UKPDS 35): Prospective observational study. BMJ 321: 405-412.

14. Ziegler D, Rathmann W, Dickhaus T, Meisinger C, Mielck A, et al. (2008) Prevalence of polyneuropathy in pre-diabetes and diabetes is associated with abdominal obesity and macroangiopathy: The MONICA/KORA Augsburg Surveys S2 and S3. Diabetes Care 31: 464-469.

15. Chahbi Z, Lahmar B, Hadri SE, Abainou L, Kaddouri S, et al. (2018) The prevalence of painful diabetic neuropathy in 300 Moroccan diabetics. Pan Afr Med J 31: 158.

16. Silverman J, Krieger J, Kiefer M, Hebert P, Robinson J, et al. (2015) The Relationship Between Food Insecurity and Depression, Diabetes Distress and Medication Adherence Among Low-Income Patients with Poorly-Controlled Diabetes. J Gen Intern Med 30: 1476-1480.

17. Schultz JL, Horner KE, Mcdanel DL, Miller ML, Beranek RL, et al. (2018) Comparing Clinical Outcomes of a Pharmacist-Managed Diabetes Clinic to Usual Physician-Based Care. J Pharm Pract 31: 268-271.

18. Siaw MYL, Ko Y, Malone DC, Tsou KYK, Lew YL, et al. (2017) Impact of pharmacist-involved collaborative care on the clinical, humanistic and cost outcomes of high-risk patients with type 2 diabetes (IMPACT): A randomized controlled trial. J Clin Pharm Ther 42: 475-482. 


\section{If}

Advances In Industrial Biotechnology | ISSN: 2639-5665

Advances In Microbiology Research | ISSN: 2689-694X

Archives Of Surgery And Surgical Education | ISSN: 2689-3126

Archives Of Urology

Archives Of Zoological Studies | ISSN: 2640-7779

Current Trends Medical And Biological Engineering

International Journal Of Case Reports And Therapeutic Studies | ISSN: 2689-310X

Journal Of Addiction \& Addictive Disorders | ISSN: 2578-7276

Journal Of Agronomy \& Agricultural Science | ISSN: 2689-8292

Journal Of AIDS Clinical Research \& STDs | ISSN: 2572-7370

Journal Of Alcoholism Drug Abuse \& Substance Dependence | ISSN: 2572-9594

Journal Of Allergy Disorders \& Therapy | ISSN: 2470-749X

Journal Of Alternative Complementary \& Integrative Medicine | ISSN: 2470-7562

Journal Of Alzheimers \& Neurodegenerative Diseases | ISSN: 2572-9608

Journal Of Anesthesia \& Clinical Care | ISSN: 2378-8879

Journal Of Angiology \& Vascular Surgery | ISSN: 2572-7397

Journal Of Animal Research \& Veterinary Science | ISSN: 2639-3751

Journal Of Aquaculture \& Fisheries | ISSN: 2576-5523

Journal Of Atmospheric \& Earth Sciences | ISSN: 2689-8780

Journal Of Biotech Research \& Biochemistry

Journal Of Brain \& Neuroscience Research

Journal Of Cancer Biology \& Treatment | ISSN: 2470-7546

Journal Of Cardiology Study \& Research | ISSN: 2640-768X

Journal Of Cell Biology \& Cell Metabolism | ISSN: 2381-1943

Journal Of Clinical Dermatology \& Therapy | ISSN: 2378-8771

Journal Of Clinical Immunology \& Immunotherapy | ISSN: 2378-8844

Journal Of Clinical Studies \& Medical Case Reports | ISSN: 2378-8801

Journal Of Community Medicine \& Public Health Care | ISSN: 2381-1978

Journal Of Cytology \& Tissue Biology | ISSN: 2378-9107

Journal Of Dairy Research \& Technology | ISSN: 2688-9315

Journal of Dentistry Oral Health \& Cosmesis | ISSN: 2473-6783

Journal Of Diabetes \& Metabolic Disorders | ISSN: 2381-201X

Journal Of Emergency Medicine Trauma \& Surgical Care | ISSN: 2378-8798

Journal Of Environmental Science Current Research | ISSN: 2643-5020

Journal Of Food Science \& Nutrition | ISSN: 2470-1076

Journal Of Forensic Legal \& Investigative Sciences | ISSN: 2473-733X

Journal Of Gastroenterology \& Hepatology Research | ISSN: 2574-2566
Journal Of Genetics \& Genomic Sciences | ISSN: 2574-2485

Journal Of Gerontology \& Geriatric Medicine | ISSN: 2381-8662

Journal Of Hematology Blood Transfusion \& Disorders | ISSN: 2572-2999

Journal Of Hospice \& Palliative Medical Care

Journal Of Human Endocrinology | ISSN: 2572-9640

Journal Of Infectious \& Non Infectious Diseases | ISSN: 2381-8654

Journal Of Internal Medicine \& Primary Healthcare | ISSN: 2574-2493

Journal Of Light \& Laser Current Trends

Journal Of Medicine Study \& Research | ISSN: 2639-5657

Journal Of Modern Chemical Sciences

Journal of Nanotechnology Nanomedicine \& Nanobiotechnology | ISSN: 2381-2044

Journal Of Neonatology \& Clinical Pediatrics | ISSN: 2378-878X

Journal Of Nephrology \& Renal Therapy | ISSN: 2473-7313

Journal Of Non Invasive Vascular Investigation | ISSN: 2572-7400

Journal Of Nuclear Medicine Radiology \& Radiation Therapy | ISSN: 2572-7419

Journal Of Obesity \& Weight Loss | ISSN: 2473-7372

Journal Of Ophthalmology \& Clinical Research | ISSN: 2378-8887

Journal Of Orthopedic Research \& Physiotherapy | ISSN: 2381-2052

Journal Of Otolaryngology Head \& Neck Surgery | ISSN: 2573-010X

Journal Of Pathology Clinical \& Medical Research

Journal of Pharmacology Pharmaceutics \& Pharmacovigilance | ISSN: 2639-5649

Journal Of Physical Medicine Rehabilitation \& Disabilities | ISSN: 2381-8670

Journal Of Plant Science Current Research | ISSN: 2639-3743

Journal Of Practical \& Professional Nursing | ISSN: 2639-5681

Journal Of Protein Research \& Bioinformatics

Journal Of Psychiatry Depression \& Anxiety | ISSN: 2573-0150

Journal Of Pulmonary Medicine \& Respiratory Research | ISSN: 2573-0177

Journal Of Reproductive Medicine Gynaecology \& Obstetrics | ISSN: 2574-2574

Journal Of Stem Cells Research Development \& Therapy | ISSN: 2381-2060

Journal Of Surgery Current Trends \& Innovations | ISSN: 2578-7284

Journal Of Toxicology Current Research | ISSN: 2639-3735

Journal Of Translational Science And Research

Journal Of Vaccines Research \& Vaccination | ISSN: 2573-0193

Journal Of Virology \& Antivirals

Sports Medicine And Injury Care Journal | ISSN: 2689-8829

Trends In Anatomy \& Physiology | ISSN: 2640-7752

Submit Your Manuscript: https://www.heraldopenaccess.us/submit-manuscript 